$\xi=-$ 娄

\title{
Effect of Welding Current on Weldments Properties in MIG and TIG Welding
}

\author{
Aysha Sh. Hasan ${ }^{1 *}$, Obed M. Ali ${ }^{2}$, Adnan M. Alsaffawi ${ }^{3}$ \\ ${ }^{1}$ Kirkuk Technical College, NorthernTechnical University, 36001 Kirkuk, Iraq \\ ${ }^{2}$ Renewable Energy Research Unit, NorthernTechnical University, 36001 Kirkuk, Iraq \\ ${ }^{3}$ Engineering College, University of Mosul, Mosul, Iraq \\ *Corresponding author E-mail: eng_aysha@yahoo.com
}

\begin{abstract}
Welding is an important process commonly used to join the different materials together. There are many methods for welding process;therefore, the specifications of weldments will depend on the type of welding process. In this study, investigation of the effect of electrical current on the weldment mechanical propertieswas conducted. Medium carbon steel \& stainless steel were welded using two types of joints (single Lap joint and single v-groove Butt joint). The results showedthat the temperature increased with increasing the electrical current. A significant effect of electrical current on the ultimate tensile strength of the weldments is obtaineddepending on the joint type rather than welding type.Furthermore, there was a noticeable effect for the joining method on the heat generated.The heat generated increases with increasing the electrical current for all weldments (lap \& butt) joint in both TIG \& MIG welding process. However,the amount of heat generated was for TIG welding process specimens higher than from MIG welding process specimens for Butt and Lap type joints.
\end{abstract}

Keywords: Medium carbon steel,MIG,Stainless steel, Tensile strength,TIG,Welding process.

\section{Introduction}

Welding is considered as a standout amongst the most normally utilized manufacture techniques in the present mechanical applications (Ismail and Fuhaid 2017).Welding is essentially a combination of at least two bits of metals by the use of heating (Oyetunji and Nwigboji 2014).TIG and MIG welding strategies arc current welding techniques in which latent and dynamic gases are utilized to keep the weld pool from climatic oxidation. Both these strategies arc circular segment welding techniquesuse electric start to produce the required heat vitality for melting the parent metals. In Tungsten latent gas welding, filler bar could be used. The usage of the filler bar depends on upon the method for the workpiece to be welded. If filler pole is used, it is industriously broken down by the twist and empowered into the weld pool. Inert gas supply is constantly given around the cathode in the midst of the welding system. The inert gas forms as gas protecting around the weld. It saves the weld from the outside air(Ismail and Fuhaid 2017).Tungsten Inert Gas (TIG) welding and Metal Inert Gas (MIG) welding processes show improve mechanical properties of stainless steel and medium carbon weldments(Mishra, Tiwari, and Rajesha 2014).The joining of stainless steels with medium carbon steels is common applications in thermal power industries, stainless steel piping is often exposed to high- temperature and pressure steam and carry on passes temperature and pressure may below a certain level, the carbon steel and alloy carbon steels pipeline perform adequately and reduce the overall cost

of the structure(B. Srinivasan, V. Muthupandi 2006).The dilution of the weld metal with the two base metals and the different coefficients of thermal expansion are two major criterions for dissimilar welding of stainless and medium carbon steels (B.C. Howard
1994).The stainless steel is the most well-known material for structural applications. Due to their magnificent physical properties yet increment the basic cost. The extra advantages and the outline codes of stainless steels have centred their mechanical use for traditional auxiliary building applications, for example, common development, atomic reactors, heatpower plants, pressure vessels and heat reactors for a few modern implementations(Gardner 2005). The very substantial engineering material is steel. The steel found in spacious uses areas like vehicle elements, automobile doors, domestic appliance etc., due to its importance as engineering materials. Welding is a very economical process for mechanical and other properties, also is usually adopted for reducing manufacturing time, reduction in weight and improvement in mechanical properties instead of classical mechanical components joining like fasteners, rivet joints etc.(Talabi et al. 2014a).Gadewar SP \&etal.(Gadewar SP, Swaminadhan P, Harkare MG 2010)studied the impact of process parameters on bead geometry of welded joints. TIG welding was performed on $3 \mathrm{~mm}$ thick 304 stainless steel. The test result shows that, as the welding current and gas flow rate increases with the thickness of the workpiece the front width and back width value across the weld was also increases from 3 to $5 \mathrm{~mm}$ for $1 \mathrm{~mm}$ thick workpiece and from 4 to $6 \mathrm{~mm}$ for $2 \mathrm{~mm}$ thick workpiece which affect the mechanical property of welds with great extent. Wang Q \&etal.(Wang Q, Sun DL, Na Y, Zhou Y, Han XL 2011)investigated the effect of different parameters like variable current, variable welding speed \& different plate thickness using TIG welding process, the results were obtained that the heat increase with increasing the current and reduction with the welding speed. Raveendra A. \&etal.(Raveendra A 2013) Outright experiment to check the influence of pulsed current on the characteristics of weldments by GTAW.The $3 \mathrm{~mm}$ thick sheet of steel was tested using different 
frequencies. More hardness found in the weld zone of all weldments may be due to grain refinement. Higher tensile strength found in the non-pulsed current weldments. The researcher observed that UTS and YS value of non-pulsed current were more than the parent metal and pulsed current weldments.Mathur A et al. (Mathur A, Muneer Md A, Sricharan S S 2015) studied the attribute of gas tungsten arc weld of AISI 304 stainless steel of $6 \mathrm{~mm}$ thickness. Welding wasperformed with variable current \& variable gas flow rate. From the analysis, it was concludedthat due to the presence of various alloying elements and post weld heat treatments the tensile strength and ductility of the base metal is significantly higher than the weld bead. Khoushid AM et al. (Khourshid AM 2016) studied the mechanical properties of welded aluminum 6061pipe using three different types of welds. Weldments with rotation speed (1800 RPM) and travel speed $4 \mathrm{~mm} / \mathrm{min}$ of MIG, TIG and Friction welding were compared. The microstructure of the welds, including the nugget zone and heat affected zone, has been compared and concluded that the microhardness values are higher in the weld region of FSW joints compared to MIG and TIG. Furthermore, FSW welds exhibit higher strength values compared to others.Generally, the weldments qualityis directly influenced by welding process parameters like electrical welding current, welding speed, the electrode diameter and voltage. Therefore, welding can be considered as a multi-input-multi-output process. Unfortunately, popular affairs to control the process input parameters to obtain good weldments with the required bead geometry and weld quality with minimal detrimental residual stresses and distortion that faced the industrialist.

\section{Materials And Methods}

The materials used in the experiments were cutting with dimensions $(80,20 \& 4) \mathrm{mm}$ shown in figures (1) \& (2).

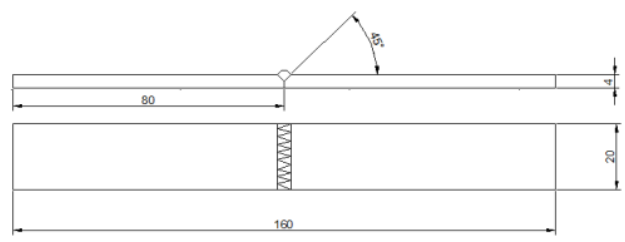

Fig.1: the dimensions of specimens for TIG \& MIG welding process $(\mathrm{mm}) /$ single-V groove butt joint
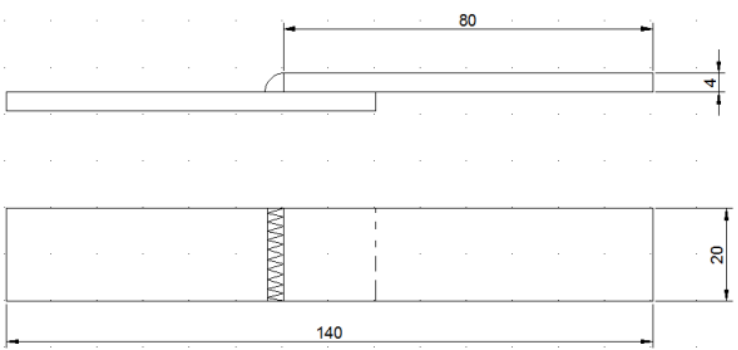

Fig.2: the dimensions of specimens for TIG \& MIG welding process $(\mathrm{mm}) /$ single lap joint

The chemical compositions of the Medium carbon steels and Stainless steels (304L) and the filler rod for specimens are shown in table-1, analyzed by material analysis division type spectro.
Table1: Chemical composition of Stainless steel, Medium carbon steel \& the filler rod for samples used in this wor

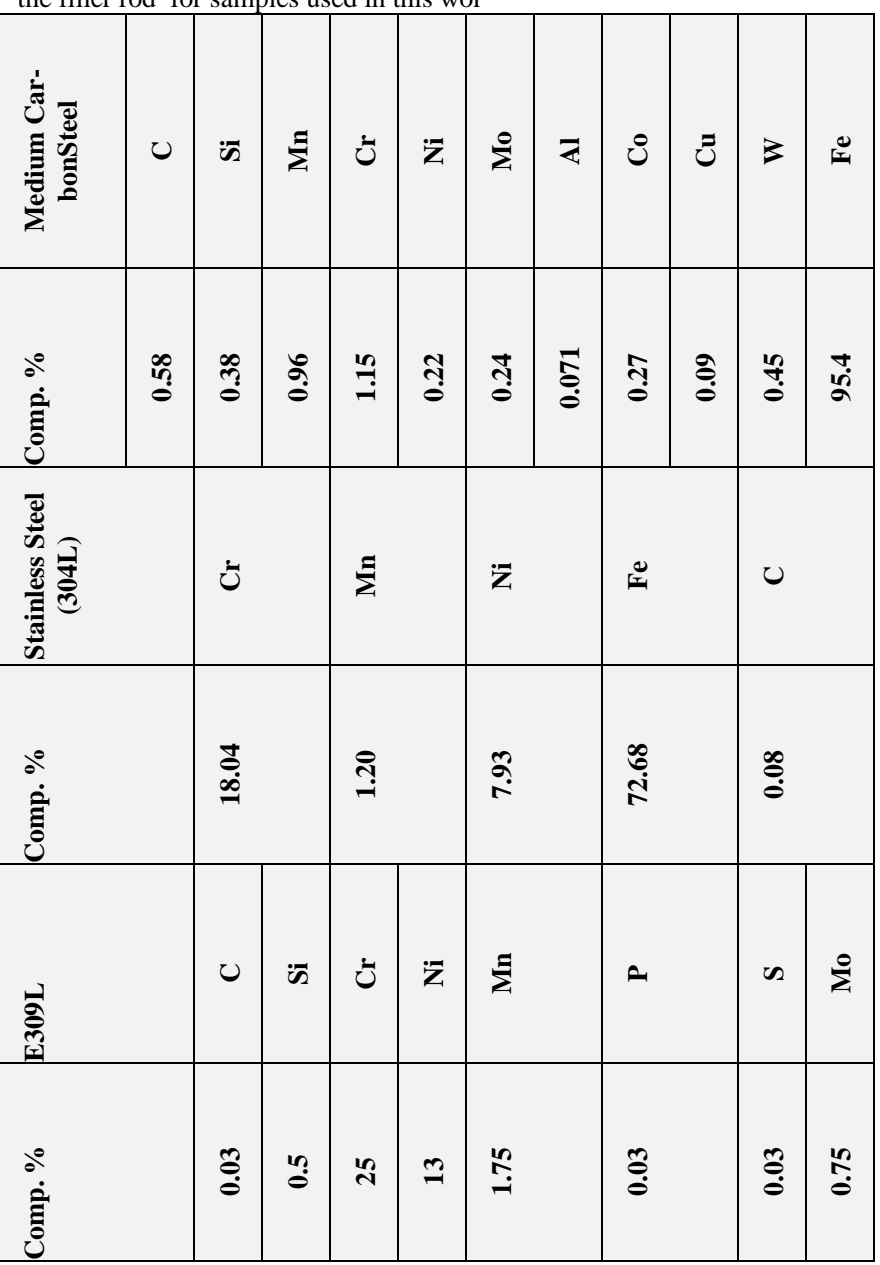

The specimens faced by using a grinding machine to prepare the weld surfaces. Then the surfaces were smoothed, with emery paper and the surfaces to be welded were cleaned with alcoholprior to welding using TIG and MIG welding machine with type TWLIN TIG 190 \&TWLIN Bmax182 respectively todifferent welding samples of Stainless steel(304L) with Medium carbon steel, shown in figure(3).

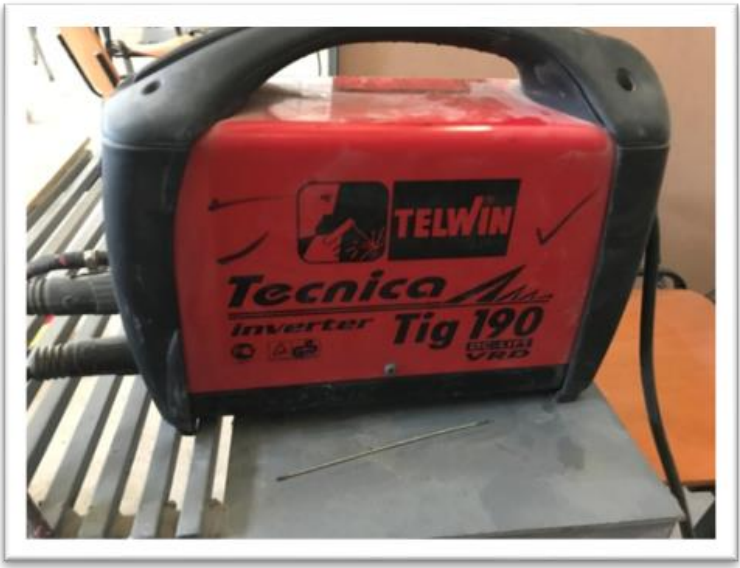

(a) 


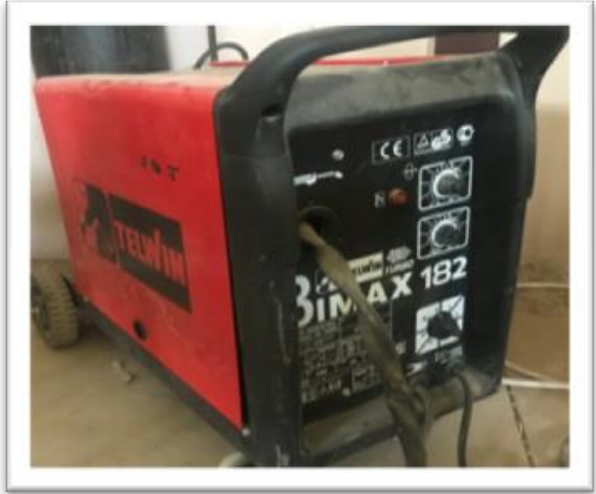

(b)

Fig.3: The welding machines were used in the work, a- TIG welding machine \& b- MIG welding machine.

The welding joint was designed ' $\mathrm{v}$ ' groove with angle of $45^{\circ}$ for butt type joint. The E309L filler rod of $1.2 \mathrm{~mm}$ diameter filler material was used for all welding process. Fixing the samples by special clips (Butt \& Lap joint) to prepare them for welding process(Voort 2004).Using an infrared thermometer,Bitemeter type record the welding temperatures with a temperature range (-50$1500 \mathrm{oC})$.Marking the samples according to the current selected by the selector of the machine shown in figure(4).

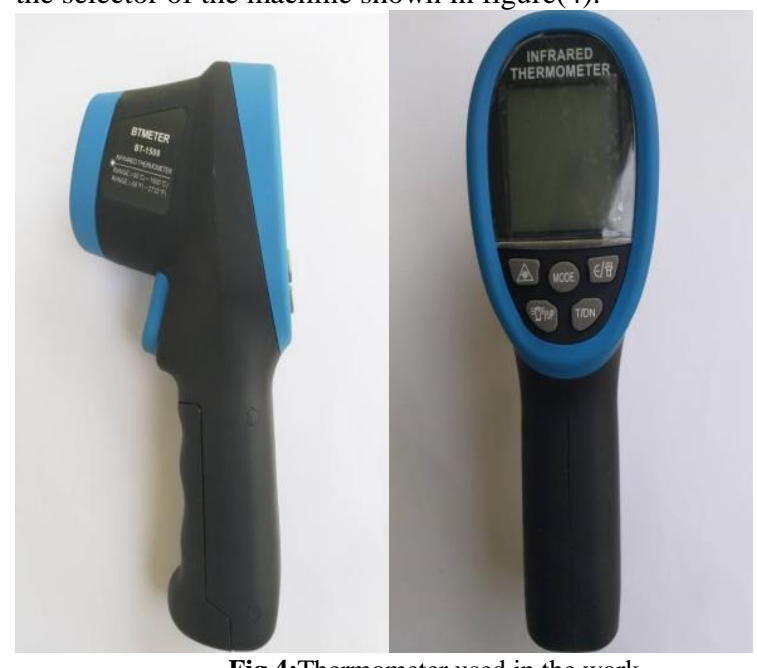

Fig.4:Thermometer used in the work

The strength of the welds were examined by carrying out tensile tests by using a universal testing machine shown in figure(5).

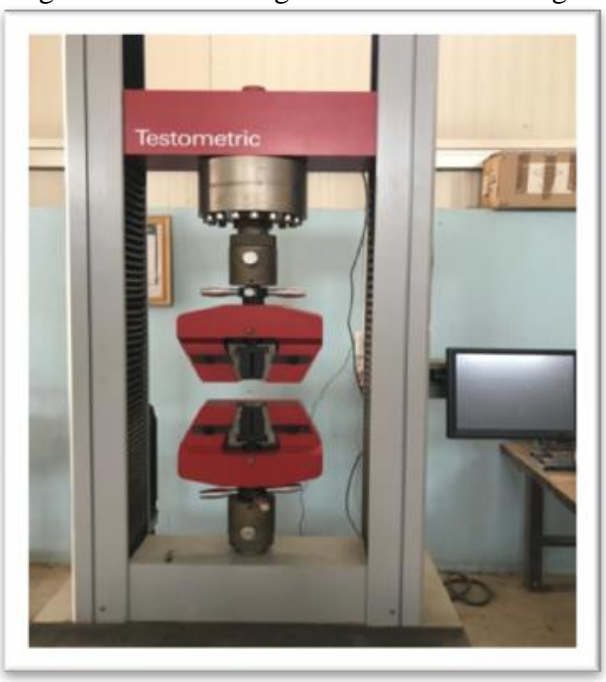

Fig.5: Tensile test machine used in the work
Each specimen was stampedusing a special permanent marker to recognize one from other and the specimen used in work shown in figure(6).

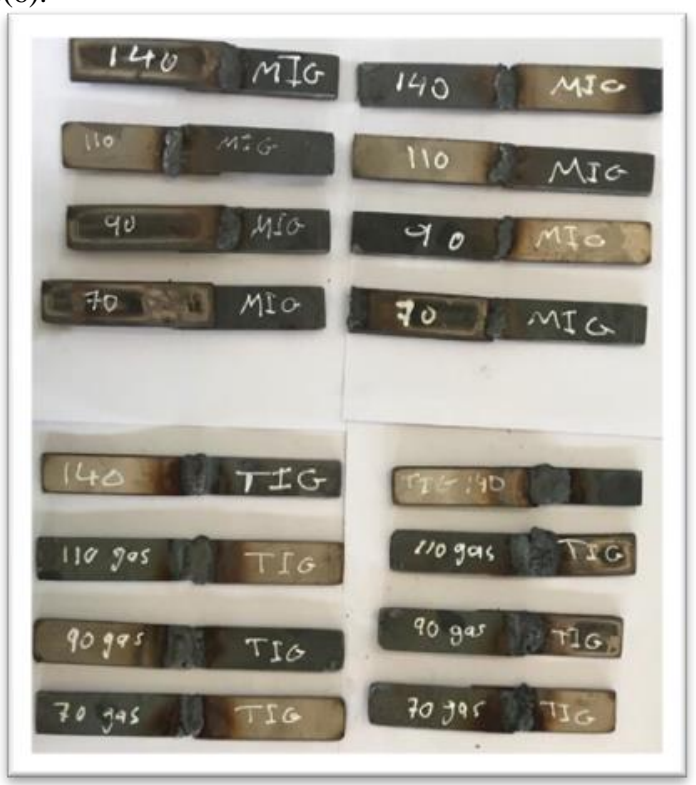

The process parameters selected for TIG and MIG welding are show in table- 2 .

Table 2: TIG and MIG welding process parameters used.

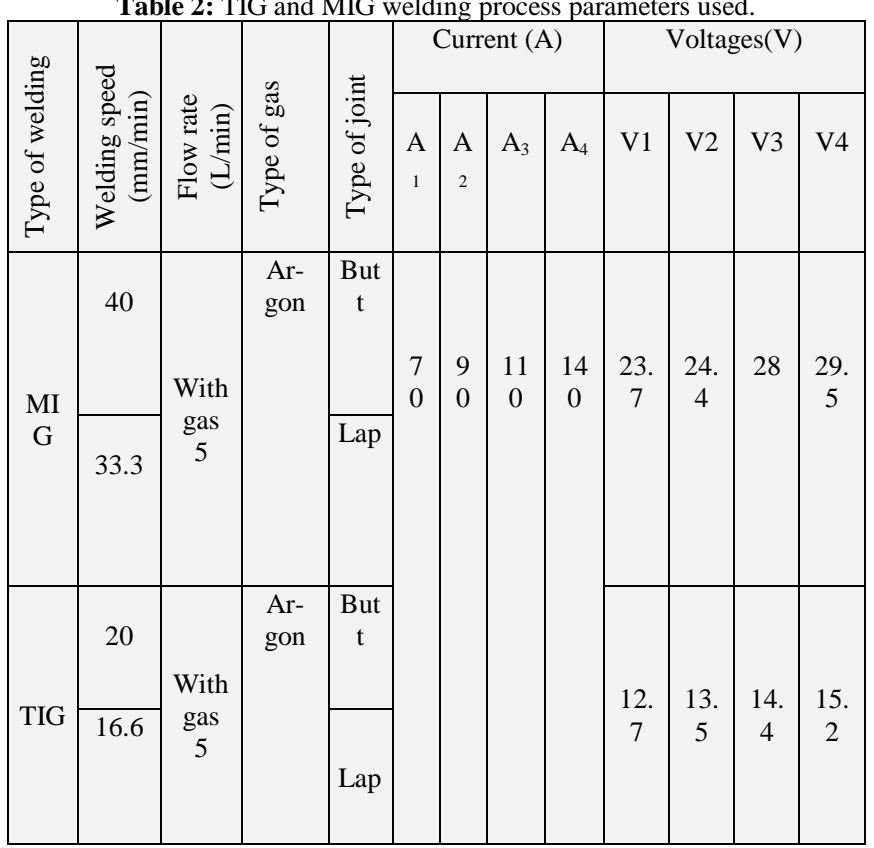

The ultimate tensile strength (UTS) was calculated from the following formula:

Ultimate Tensile

Strength $(\mathrm{UTS})=\frac{\mathrm{F}}{\mathrm{A}}$

Where:

Ultimate Tensile Strength (UTS) in MPa.

$\mathrm{F}$ : is the maximum ultimate force in the test in $\mathrm{kN}$.

A: is the cross section area of the specimens in $\mathrm{m} 2$ (Roylance 2008).

And the amount of heat generated is calculated as a function of current, voltage and welding speed is expressed according to Joules law by the formula:

$\mathrm{Q}=\frac{\mathbb{W} * 60}{\mathrm{5} 1000}$ 
Where:

Q: Heat generated $(\mathrm{kJ} / \mathrm{mm})$

I: Current (Ampere)

V: Voltage (V)

S: Welding speed (mm/min)(Anand Rao and Deivanathan 2014)

\section{Results And Discussion}

In this study, investigation of the effect of electrical current on the weldment mechanical properties was conducted. Medium carbon steel \& stainless steel were welded using two types of joints (single Lap joint and single v-groove Butt joint). Table- 3 presents the temperature values that obtained from welding process with each used current. In Table- 4 the peak force values were listed from the tensile test to compare the welding and joint type. The elongation values that obtained from welding process is listed in Table-5for each welding and joint type.

Table3: the temperature values were obtained from the welding process

\begin{tabular}{|c|c|c|c|c|c|}
\hline \multirow{3}{*}{ Type of welding } & \multirow{2}{*}{ Type of joint } & \multicolumn{5}{|c|}{ Temperature $\left({ }^{\circ} \mathrm{C}\right)$} \\
\cline { 3 - 6 } & & $\mathbf{7 0 A}$ & $\mathbf{9 0 A}$ & $\mathbf{1 1 0 A}$ & $\mathbf{1 4 0 A}$ \\
\hline \multirow{3}{*}{ MIG } & Butt & 950 & 983 & 991 & 1027 \\
\cline { 3 - 6 } & Lap & 1115 & 1117 & 1137 & 1155 \\
\hline \multirow{3}{*}{ TIG } & Butt & 1000 & 1143 & 1343 & 1410 \\
\cline { 2 - 6 } & & 1172 & 1265 & 1311 & 1378 \\
& Lap & & & & \\
\hline
\end{tabular}

Table4: the peak force values obtained from tensile test

\begin{tabular}{|c|c|l|c|c|c|}
\hline Type of welding & Type of joint & \multicolumn{5}{|c|}{ Peak Force $(\mathrm{kN})$} \\
\cline { 3 - 6 } & & $70 \mathrm{~A}$ & $90 \mathrm{~A}$ & $110 \mathrm{~A}$ & $140 \mathrm{~A}$ \\
\hline \multirow{3}{*}{ MIG } & Butt & 39.370 & 28.280 & 42.250 & 45.590 \\
\cline { 2 - 6 } & Lap & 18.620 & 29.700 & 54.55 & 83.490 \\
\hline \multirow{2}{*}{ TIG } & Butt & 16.100 & 44.230 & 42.840 & 71.37 \\
\cline { 2 - 6 } & Lap & 15.620 & 24.56 & 24.300 & 52.11 \\
\hline
\end{tabular}

Table5:The elongation values were obtained from tensile test

\begin{tabular}{|c|c|l|l|l|l|}
\hline \multirow{2}{*}{ Type of welding } & Type of joint & \multicolumn{4}{|c|}{ \%Elongation } \\
\cline { 3 - 6 } & & $70 \mathrm{~A}$ & $90 \mathrm{~A}$ & $110 \mathrm{~A}$ & $140 \mathrm{~A}$ \\
\hline \multirow{2}{*}{ MIG } & Butt & 10.4 & 3.787 & 6.670 & 9.57 \\
\cline { 2 - 6 } & Lap & 5.840 & 3.312 & 13.87 & 9.681 \\
\hline \multirow{2}{*}{ TIG } & Butt & 2.463 & 3.075 & 2.859 & 7.263 \\
\cline { 2 - 6 } & Lap & 7.23 & 1.928 & 1.701 & 3.703 \\
\hline
\end{tabular}

Figure 7 shows the relation of welding current with the obtained temperature for the two types of welding (MIG \& TIG) lap joint.Drastic increase of welding temperature with current has been observed for TIG lap welding withincreasing current values used in this research for all specimens. The maximum temperature valueobserved for TIG welding was $1378 \mathrm{oC}$ at $140 \mathrm{~A}$ welding current. Meanwhile the minimum temperature valuefound to be $1115 \mathrm{oC}$ at the $70 \mathrm{~A}$ For MIG welding. The insignificant increase of welding temperature with current has been observed for MIG lap welding with all current used in this research for all specimens. In general, the temperature values were in TIG weldments higher than for MIG weldments for all specimens welded laptypes joint. The general increase in temperature with increasing in electrical current can be explained by equation (2).

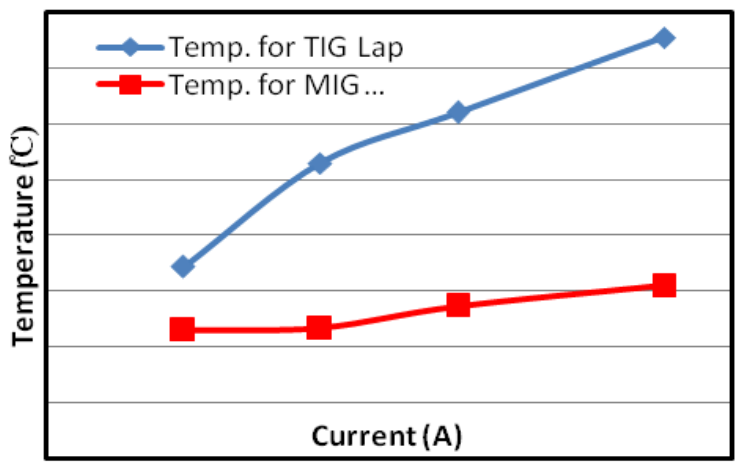

Fig.7: Temperature of welding process for (TIG \& MIG) lap joint.

Figure 8 shows the relation of welding current with the obtained temperature for the two types of welding (MIG \& TIG) butt joint. Drastic increase of welding temperature with current has been observed for TIG butt welding with increasing current values used in this research for all specimens. The maximum temperature value observed for TIG welding was $1410 \mathrm{oC}$ at $140 \mathrm{~A}$ welding current. Meanwhile the minimum temperature value found to be $950 \mathrm{oC}$ at the $70 \mathrm{~A}$ For MIG welding. The insignificant increase of welding temperature with current has been observed for MIG butt welding with all current used in this research for all specimens. In general, the temperature values were in TIG weldments higher than for MIG weldments for all specimens welded butt types joint.

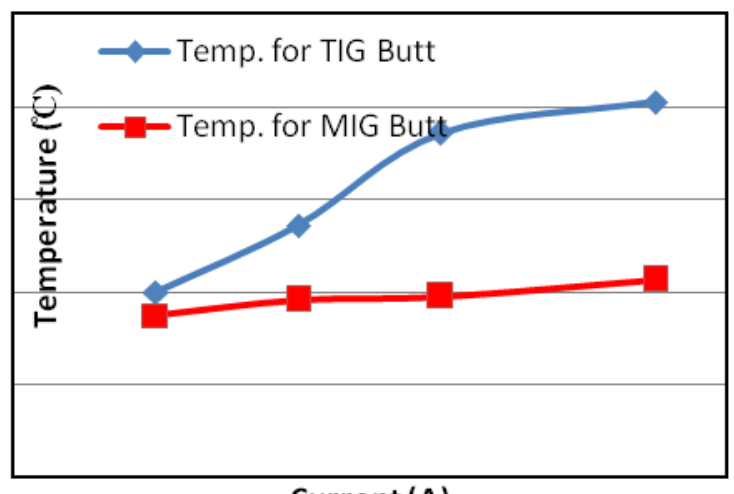

Fig.8:Temperature of two types welding process ( TIG\& MIG) butt joint

All these behaviours in figures $7 \& 8$, maybe to the time of welding in TIG is greater than the MIG welding process for two types of joints (butt \& lap). Therefore this causes melt in the HAZ zone in TIG more than MIG welding process and increases in the temperature of weldments.

Figure 9 shows that the ultimate tensile strength values for (TIG \& MIG) lap joint welding process increase with current for both welding types, this is reported by researchers in (Wang Q, Sun DL, $\mathrm{Na}$ Y, Zhou Y, Han XL 2011). For TIG lap joint specimens the maximum ultimate tensile strength value was at the current $140 \mathrm{~A}$, and the minimum ultimate tensile strength value was at the current 70A. However,the specimens were welded by MIG lap joint had the same behaviour.In general, the weldments were welded by TIG process had ultimate tensile strength lower than from the weldments were weld by MIG process for the lap joints type. Moreover, the TIG welding process needs more time to weld the specimens than the MIG welding process, therefore may be the grain refinement in the weld zone happened, all these behaviour reported by researchers in (Raveendra A 2013). 


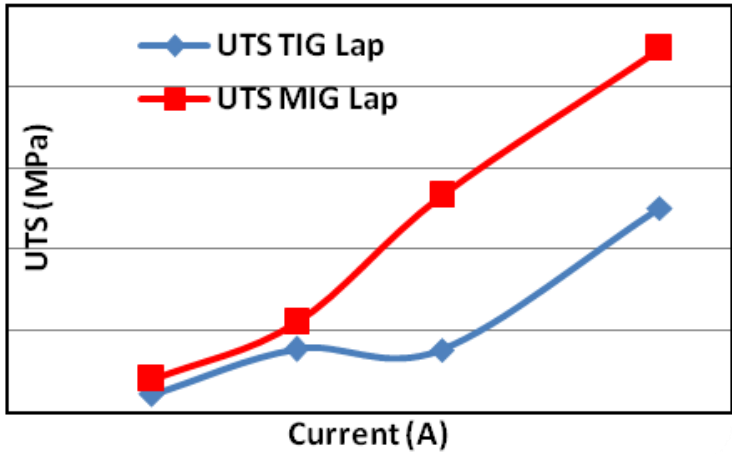

Fig.9: UTS values for (TIG\& MIG) lap jointwelding process.

Figure 10 shows that the ultimate tensile strength values for TIG \&MIGbuttjointweldingprocessfluctuated with current for both welding types, this was reported by researchers in (Talabi et al. 2014b). For the TIG butt, joint specimens the maximum ultimate tensile strength value was at the current $140 \mathrm{~A}$,and the minimum ultimate tensile strength value was at the current 70A. Meanwhile, the maximum ultimate tensile strength value at $140 \mathrm{~A}$ for the specimens was welded by MIG butt joint and minimum ultimate tensile strength value was at current 70A.In general, the ultimate tensile strength values for the weldments were welded by TIG higher than from the weldments were welded by MIG process for all specimens butt type joints expect at current 70A. In general, the TIG welding process needs more time to weld the specimens than the MIG welding process, therefore may be the grain refinement in the weld zone happened, all these behaviour reported by researchers in (Raveendra A 2013).

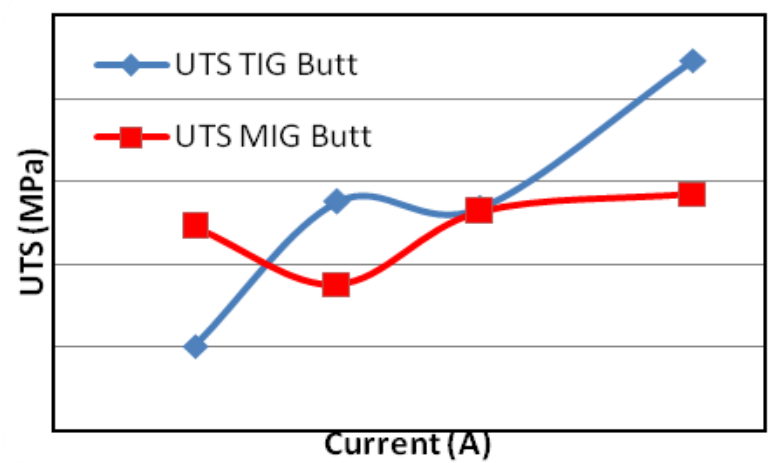

Fig.10: UTS values for (TIG \& MIG) butt jointwelding process.

Figure 11 shows the comparison between butt \& lap joints weldments for TIG welding process. In general, the ultimate tensile strength values for weldments butt joint types was higher than from the lap joint types for all weldments welded by TIG welding process; this is may be due to grain refinement, this is reported by a researcher in (Raveendra A 2013).Figure 12 shows the comparison between butt $\&$ lap joints weldments for MIG welding process. Whatever for the weldments welded by MIG welding process the lap joints type specimens had higher values than from specimens welded by butt type joints.

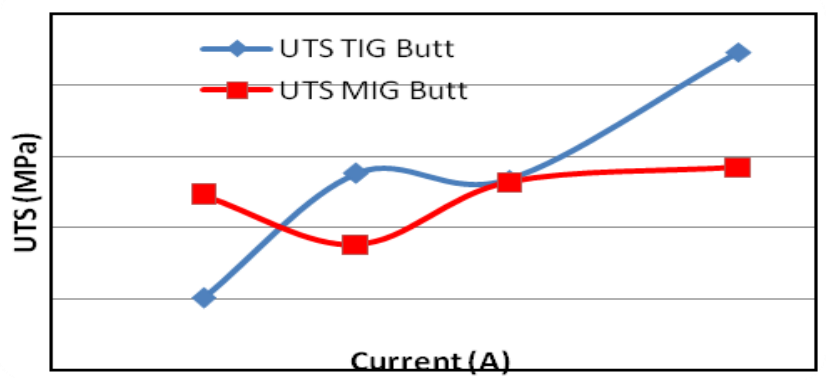

Fig.11: Shows the comparison between butt \& lap joints weldments for TIG welding process

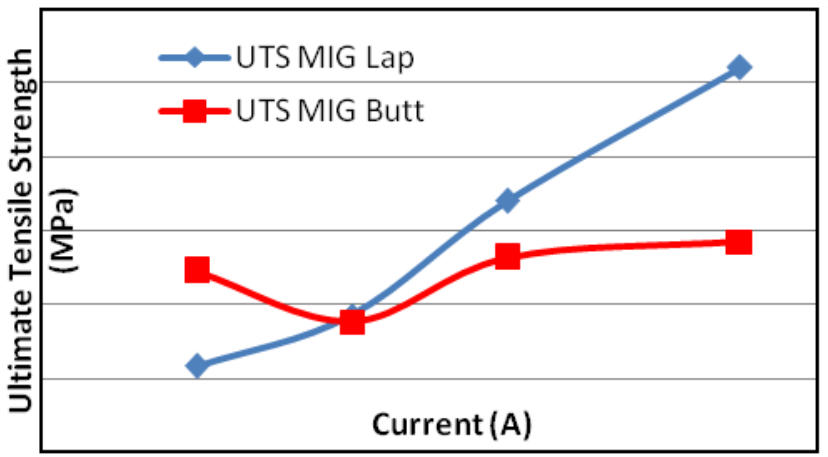

Fig.12: Shows the comparison between butt \& lap joints weldments for MIG welding process

All these behaviours in figures $9,10,11 \& 12$ are due to TIG welding process temperatures values for specimens which were higher than the MIG welding process temperature values. This because the welding time was greater in TIG than MIG due to the manual feeding in TIG meanwhile automatic feeding in MIG and the greater time causes an increase in the temperature which may be caused grain refinements in the welding zone HAZ and this will directly proportional with the ultimate tensile strength.

Figure 13 shows the amount of heat generated for the two types welding process TIG \& MIG butt joint. Figure 14 shows the amount of heat generated for two types of welding process TIG \& MIG lap joint. The amount of heat generated was for TIG welding process specimens higher than from MIG welding process specimens for Butt and Lap type joints, thisbehaviourdue to high welding speed values in MIG welding process comparing to the values in TIG welding process, according to the equation(2). The amount of heat generated was increasing with increasing the current to all specimens used in work, this was reported by researchers in (Wang Q, Sun DL, Na Y, Zhou Y, Han XL 2011).

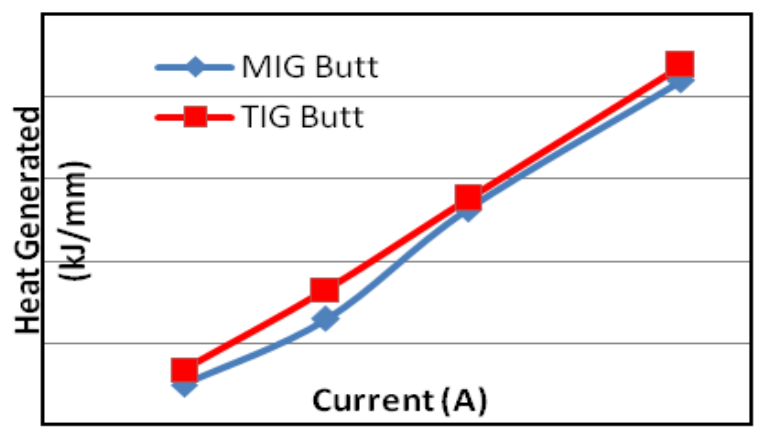

Fig.13: The two types welding process (TIG \& MIG) butt joint, the amount of heat generated

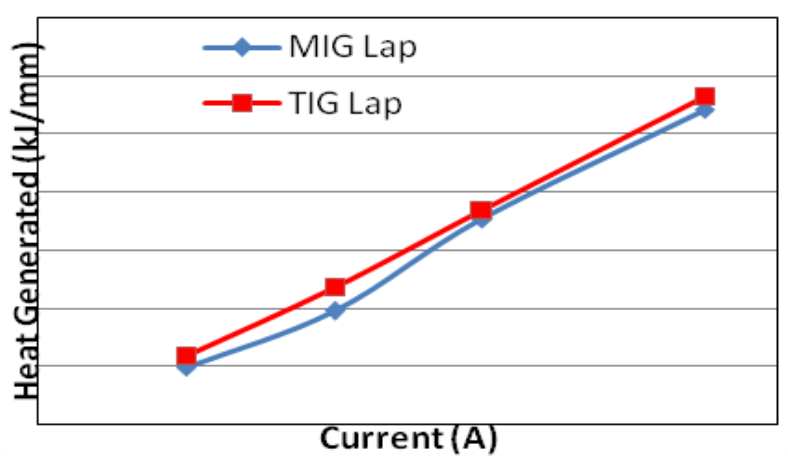

Fig.14: Two types of welding process (TIG \& MIG) lap joint, the amount of heat generated

Figure 15 shows the amount of heat generated of the butt \& lap joint type for MIG welding process; Figure 16 shows the amount of heat generated of the butt \& lap joint type for TIG welding 
process. The amount of heat generated was for lap type joints specimens higher than for MIG \& TIG welding process specimens from butt type joints. This trend may attribute to the large amount of heat that affected to the welding zone to capable the weldments to join well.

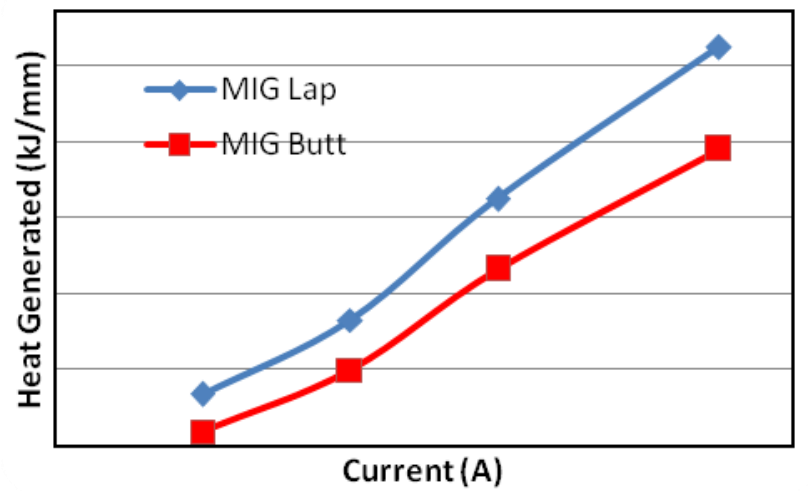

Fig.15: Two types of joints lap \& butt, the amount of heat generated for MIG welding process

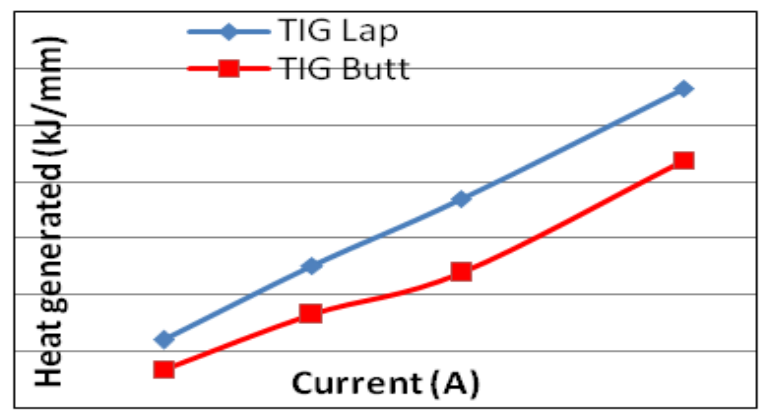

Fig.16:Two types of joints lap \& butt, the amount of heat generated for TIG welding process

In this study, investigation of the effect of electrical current on the weldment mechanical properties was conducted. Medium carbon steel \& stainless steel were welded using two types of joints (single Lap joint and single v-groove Butt joint).

The results showed a significant increase of welding temperature with current for TIG lap welding andan insignificant increase of welding temperature with current for MIG lap welding with all current used in this research for all specimens

In general, the temperature values were in TIG weldments higher than from MIG weldments for all specimens welded lap \& butt types joints. The ultimate tensile strength values for weldments butt joint types was higher than from the lap joint types for all weldments welded by TIG welding process.

The amount of heat generated was for TIG welding process specimens higher than from MIG welding process specimens for butt and lap type joints.

\section{Conclusions}

In this study, investigation of the effect of electrical current on the weldment mechanical properties was conducted. Medium carbon steel \& stainless steel were welded using two types of joints (single Lap joint and single v-groove Butt joint).

The results showed a significant increase of welding temperature with current for TIG lap welding andan insignificant increase of welding temperature with current for MIG lap welding with all current used in this research for all specimens.

In general, the temperature values were in TIG weldments higher than from MIG weldments for all specimens welded lap \& butt types joints.
The ultimate tensile strength values for weldments butt joint types was higher than from the lap joint types for all weldments welded by TIG welding process.

The amount of heat generated was for TIG welding process specimens higher than from MIG welding process specimens for butt and lap type joints

\section{References}

[1] Anand Rao, V., and R. Deivanathan. 2014. "Experim -ental Investigation for Welding Aspects of Stainless Steel 310 for the Process of TIG Welding." Procedia Engineering 97. Elsevier B.V.: 902-908. doi:10. 1016/j.proeng.2014.12.365.

[2] B. Srinivasan, V. Muthupandi, W. Dietzel \& V. Sivan. 2006 "An Assessment of Impact Strength and Corrosion Behaviour of Shielded Metal Arc Welded Dissimilar Weldments between UNS 31803 and IS 2062 Steels." Materials Science and Technology (United Kingdom) 3 (27): 182-191.

[3] B.C. Howard. 1994. Modern Welding Technology. Prentice-Hall, New Jerse.

[4] Gadewar SP, Swaminadhan P, Harkare MG, Gawande SH. 2010. "Experimental Investigation of Weld Characteristics for a Single Pass TIG Welding with SS304.” International Journal of Engineering Science and Technology 2 (8): 3676-3686.

[5] Gardner, L. 2005. "The Use of Stainless Steel in Structures." Prog. Struct. Engng. Mater 7: 48-55.

[6] Ismail, Aisha A L, and Mutlag Shafi Fuhaid. 2017. "An Experimental Analysis On Mechanical Integrity Of Tig-Mig Hybrid Weldments." International Journal of Mechanical And Production Engineering 5 (4): 114-117.

[7] Khourshid AM, Ibraheem S. 2016. "Analysis of Welded Joints Using Friction Stir Welding, Metal Inert Gas and Tungsten Inert Gas." Engineering and Technology in India 7 (1): 1-7.

[8] Mathur A, Muneer Md A, Sricharan S S, Chandra Shekar K. 2015. "Gas Tungsten Arc Welding of AISI 304 Austenitic Stainless Steels." International Journal of Engineering Research \& Technology 4 (15): 148-150.

[9] Mishra, Radha Raman, Visnu Kumar Tiwari, and S. Rajesha. 2014. "A Study of Tensile Strength of MIG and TIG Welded Dissimilar Joint of Mild Steel and Stainless Steel." International Journal of Advances in Materials Science and Engineering (IJAMSE) 3 (2): 23-32. doi:10.14810/ijamse. 2014. 3203.

[10] Oyetunji, Akinlabi, and Nwafagu Nwigboji. 2014. "Effect of Welding Process, Type of Electrode and Electrode Core Diameter on the Tensile Property of 304L Austenitic Stainless Steel." Leonardo Electronic Journal of Practices and Technologies 13 (25): 210-222.

[11] Raveendra A, Kumar BR. 2013. "Experimental Study on Pulsed and Non-Pulsed Current TIG Welding of Stainless Steel Sheet (SS304)." International Journal of Innovative Research in Science, Engineering and Technology 2 (6): 2337-2344.

[12] Roylance, David. 2008. Mechanical Properties of Materials.

[13] Talabi, S. I., O. B. Owolabi, J. A. Adebisi, and T. Yahaya. 2014a. "Effect of Welding Variables on Mechanical Properties of Low Carbon Steel Welded Joint." Advances in Production Engineering \& Management 9 (4): 181-186. doi:10.14743/apem 2014. 4.186.

[14] Talabi, S I, O B Owolabi, J A Adebisi, and T Yahaya. 2014b. "Effect of Welding Variables on Mechanical Properties of Low Carbon Steel Welded Joint." Advances in Production Engineering \& Management 9 (4): 181-186. doi:10.14743/ apem2014. 4.186

[15] Voort, George F. Vander, ed. 2004. Metallurgaphy and Microstructure. ASM International.

[16] Wang Q, Sun DL, Na Y, Zhou Y, Han XL, Wang J. 2011. "Effects of TIG Welding Parameters on Morphology and Mechanical Properties of Welded Joint of Ni-Base Superalloy. Procedia Engineering 